CFRI

11,2

Received 2 November 2019 Revised 31 May 2020 Accepted 6 July 2020

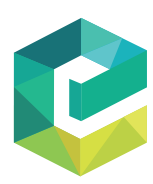

China Finance Review International Vol. 11 No. 2, 2021 pp. 230-258 Emerald Publishing Limited 2044-1398

DOI 10.1108/CFRI-11-2019-0152

\section{The inverted U-shaped relationship between crowdfunding success and reward options and the moderating effect of price differentiation

\author{
Zhigang Cai and Pengzhu Zhang
} \\ Antai College of Economics and Management, Shanghai Jiao Tong University, Shanghai, China, and \\ Xiao Han \\ School of Business, Qingdao University, Qingdao, China}

\begin{abstract}
Purpose - The paper is to explore crowdfunding success determinants from the reward menu design aspect, distinguishing from extant studies focusing on characteristics of project creators or crowdfunding projects and funding dynamics. Both the number of reward options and price differentiation of rewards are considered.

Design/methodology/approach - The authors use the quadratic model to identify a curvilinear relationship between the number of reward options and crowdfunding success, by running regressions on data collected from one of the most influential reward-based crowdfunding platforms in China. In addition, they explore the moderating effect of price differentiation on the curvilinear relationship.

Findings - The authors find an inverted U-shape relationship between the number of reward options and the optimal number of options is around 10. In addition, they find that the curvilinear relationship is moderated by reward price differentiation.

Practical implications - This paper has managerial implications for crowdfunding project creators and platform managers. To achieve better crowdfunding outcomes, a proper number of reward options with diversified reward prices should be provided.

Originality/value - The paper contributes to the literatures in antecedents of crowdfunding success from reward menu design aspect based on theories in investment and purchasing decision making. It is different from existing studies focusing on the characteristics of project creators and crowdfunding projects or funding dynamics. It also parallels retirement contribution plan design studies by exploring the reward menu design in the crowdfunding context.
\end{abstract}

Keywords Crowdfunding, Reward menu design, Inverted U-Shape, Reward options, Price differentiation Paper type Research paper

\section{Introduction}

Crowdfunding has become an important alternative financial approach for small entrepreneurs and medium-sized firms. It allows entrepreneurs to raise a small amount of funds from a large number of individuals, through a crowdfunding platform and avoids high interest rates and barriers associated with conventional forms of funding. There are mainly

(C) Zhigang Cai, Pengzhu Zhang and Xiao Han. Published by Emerald Group Publishing Limited. This article is published under the Creative Commons Attribution (CC BY 4.0) licence. Anyone may reproduce, distribute, translate and create derivative works of this article (for both commercial and noncommercial purposes), subject to full attribution to the original publication and authors. The full terms of this licence may be seen at http://creativecommons.org/licences/by/4.0/legalcode

The authors would like to thank the support from the Foundation for Innovative Research Groups of the National Natural Science Foundation of China (grant no. 71421002). 
four types of crowdfunding platforms - reward-based, debt-based, equity-based and donation-based platforms - differing from each other by different returns provided to backers. In this paper, we explore reward-based crowdfunding projects, which provide rewards as returns to backers. The rewards in one crowdfunding project are usually products or services related to the project and are provided in different quality and prices. A detailed case of reward-based crowdfunding project is provided in Appendix. With the convenience for small startups to raise money, crowdfunding has opened up a brand new market with high value. Since its infancy, the crowdfunding volume has increased to US $\$ 5319.2$ million in 2018 (Statista, 2019). Despite the increasing volume of crowdfunding, the success rate has remained modest, e.g. the average success rate of world's largest crowdfunding platform, Kickstarter, was only $36.96 \%$ in 2018 .

Therefore, researchers have focused on the antecedents of crowdfunding success, mostly from project creators' characteristics crowdfunding projects' characteristics and investment dynamics. More specifically, representative studies of crowdfunding success factors include project creators' social capital (Bapna, 2019; Beier and Wagner, 2015), gender bias (Chen et al., 2020; Gafni et al., 2019b), culture and geography differences (Burtch et al., 2013; Lin and Viswanathan, 2016), descriptions styles of projects' pitches (Dorfleitner et al., 2016; Gafni et al., 2019a; Zhou et al., 2018), and information cascades among individual investors (Vismara, 2018) .

Although factors influencing crowdfunding success go beyond the attributes of projects, creators and investment dynamics, there is a marked paucity in studying characteristics of reward menu as an additional mechanism that influences crowdfunding success (Cai et al., 2017; Hu et al., 2015). One common interest in reward menu is the effect of the number of reward options on project success. However, extant studies in this area are not conclusive, and the results from different studies are contradictory. Some researchers find that the number of reward options has a positive effect on crowdfunding success (Kunz et al., 2017; Zhou et al., 2018) because a wider range of choices increases the likelihood that backers will find a preferred option (Baumol and Ide, 1956; Lancaster, 1990) and because of better price discrimination (Hardy, 2013). On the other hand, researchers also find a negative interaction between the number of reward options and crowdfunding success (Chen et al., 2016; Leite and Moutinho, 2012) because of information overload from choice proliferation (Agnew and Szykman, 2005; Kida et al., 2010). In addition, other studies find that the effect of the number of reward options on crowdfunding success remains implicit (Frydrych et al., 2014).

These results posit a confusing phenomenon for academia and industry. Considering either the decision freedom effect or the information overloading effect may occur depending on the size of the reward menu, our study tries to answer whether there exists an inverted Ushaped relationship between the number of reward options and crowdfunding outcome and how this relationship is moderated by prices of the rewards.

To explore our research questions, we collect observational data from Zhongchou.com, one of China's most impactful reward-based crowdfunding platforms. Since its inception in 2013, Zhongchou had hosted more than 68,000 projects and solicited more than 250 million Renminbi (RMB for abbreviation) from approximately 1.6 million backers in 2017. Zhongchou host crowdfunding projects in different categories, including agriculture, publishing, entertainment, art, technique, charity and others. Our observational period is from January 2014 to December 2015. In our observation period, we collected data from approximately 9,314 projects, including the projects' attributes, project creators' information and the crowdfunding outcomes of these projects.

Our empirical analysis finds an inverted U-shaped relationship between the number of reward options and the success rate, with an optimal number of reward options around 10. When the number of reward options is low, an enlarged set of choices provides more freedom of choice for backers and enables them to find their optimal option. However, if the choice set 
CFRI 11,2

232

is too large, information overload from choice proliferation occurs because backers must process a large cognitive load for decision making. In addition, we find that reward price differentiation moderates the curvilinear relationship between the number of reward options and crowdfunding success because differentiated prices can serve as diagnostic cues when comparing unfamiliar choices in the crowdfunding context.

This paper adds to the literature on crowdfunding success determinants from a new perspective, reward menu design, which is distinct from existing studies focusing on characteristics of creators and projects or investing dynamics. It also parallels studies in pension plan design by exploring the rewards menu design in the crowdfunding context. In addition to the theoretical contribution, this paper also has managerial implications for crowdfunding project creators and platform managers. To achieve better crowdfunding outcomes, a proper number of reward options with dispersed reward prices should be provided.

\section{Literature review}

\subsection{Antecedents of crowdfunding success}

Researchers have investigated crowdfunding success factors broadly since a low success rate remains an important issue for most crowdfunding platforms. Except few studies exploring this issue from platform level, including the effect from regulation policy uncertainty (Li et al., 2017), the certification effect from venture capital (Li et al., 2020) or the due diligence policy of the platform (Cumming et al., 2019), most extant studies explore crowdfunding success determinants from project level and can be categorized into three aspects by the three relevant entities engaged in crowdfunding process: project creators, crowd backers, and crowdfunding projects.

Studies on project creators find that the creator's actions on the website, the signals about their human and social capitals and reputation formation have positive effects on crowdfunding success. More specifically, the project creators' actions, including interacting with backers and updating project progress, display their endeavors and establish credibility and legitimacy during the crowdfunding process (Block et al., 2018; Wang et al., 2018). Other studies find that the positive signals about the project creators' human and social capitals have a positive effect on crowdfunding success, which includes their educational information (Ahlers et al., 2015; Piva and Rossi-Lamastra, 2018), external endorsement from third-party authorities (Bapna, 2019; Ralcheva and Roosenboom, 2016), and their social network information (Ge et al., 2017; Vismara, 2016). In addition, entrepreneur reputation formation through past delivery performance and prior crowdfunding outcomes affects capital formation outcomes organically (Li and Martin, 2019).

A second stream of studies about backers investigates the dynamic influence between backers' contribution behaviors (Burtch et al., 2013, 2014a) and the geography (Lin et al., 2013) or cultural distances (Burtch et al., 2014b) between the project creator and the backers. The effect of dynamic contribution behaviors among backers has been broadly investigated, including the findings of the rational herding (Zhang and Liu, 2012), the prism effect from friendship (Liu et al., 2015) and observational learning from existing contributions (Burtch et al., 2013). Especially, the actions of high-profile investors and large investment during the early stages of funding cycle lead to higher crowdfunding success (Vismara, 2018). In addition, studies on the distances between project creators and backers from both cultural and geographical aspects find that distance has a negative effect on crowdfunding outcome even though the Internet may free the creators and the backers from the restriction of distances (Burtch et al., 2014b; Lin et al., 2013).

A third stream of studies focuses on the aspect of crowdfunding project characteristics, which include project pitches, target amount, funding duration and project type. A relatively 
comprehensive study of the characteristics of crowdfunding projects from Chen et al. (2016) proposes a theoretical framework for crowdfunding appeals. Through a regression-based study of a stratified sample of 200 campaigns, they find guilt appeals, utilitarian product types, an emotional message frame and reward tiers are positively and significantly related to the ultimate funding level. In line with this study, Zhou et al., (2018) use the text mining method to find the relationship between crowdfunding success and the project description (Zhou et al., 2018). They find that antecedents from the content (length, readability and tone) and trustworthiness indicators (past experience and past expertise) of project descriptions are significantly related to crowdfunding success. Similar study explores description-text related soft information in debt-based crowdfunding and draws the conclusion that spelling errors, text length and mentioning of positive emotion evoking keywords predict the funding probability (Dorfleitner et al., 2016). Besides, self-presentation in project pitches is associated with higher levels of trust and has a positive effect on crowdfunding success (Gafni et al., 2019a). In addition to the text analysis in project description part, videos have been examined to increase success probability of loan because of increased creditworthiness and reduced transaction risk (Wang et al., 2019).

Despite studies from the above three aspects, researchers also investigate the relationship between reward menu design and crowdfunding success. Related studies have investigated the number of reward options (Chen et al., 2016; Zhou et al., 2018), the limitedness of rewards (Weinmann et al., 2017), middle option bias (Simons et al., 2017), the decoy effect of similar rewards (Tietz et al., 2016) and hybrid funding schemes (Cai et al., 2017; Du et al., 2019). However, among these studies, researchers find different results of the effect of the number of reward options. On the one hand, extant studies find a positive relationship between the number of reward options and crowdfunding success (Kunz et al., 2017; Zhou et al., 2018). On the other hand, studies from Chen et al. (2016) and Leite and Moutinho (2012) find an opposite effect, a significant negative relationship. However, other studies find that the relationship is implicit and not significant (Frydrych et al., 2014). Based on the inconclusive findings about the relationship between crowdfunding success and the number of reward options, we try to determine the reasons for the contradictory findings and obtain a cohesive result anchored in the literature of assortment size and assortment pricing.

\subsection{Assortment design}

Economists, marketers and consumer behaviorists have broadly studied the effects of assortment size. Both positive and negative effects of enlarging assortment size are examined.

On the one hand, researchers study the positive effect of large assortment size from perspective including consumers' utility and decision efficiency as well as the performance of brands or stores. Utility studies have found that a larger assortment size increases the chance for an optimal choice (Wright and Barbour, 1975) or increases the probability of a perfect match (Baumol and Ide, 1956; Hotelling, 1929), offering consumers the psychological value of the freedom to choose (Reibstein et al., 1975) or satisfying their innate desire to consume different alternatives (McAlister, 1982). Studies in decision efficiency have found that a large assortment size maintains the flexibility inherent in a varied assortment (Kahn and Lehmann, 1991), offers greater efficiency in identifying the available alternatives (Betancourt and Gautschi, 1990; Messinger and Narasimhan, 1997), and hence helps consumers make the final choice (Glazer et al., 1991). In addition to the studies from the consumer perspective, other studies focus on the effect of assortment size on the performance of the brand or the store. They find that the reduction in assortment reduces overall store sales and decreases both sales frequency and quantity (Borle et al., 2005; Sloot et al., 2006). Researchers also find that the number of brands offered in a retail assortment has a positive effect on store choice (Briesch et al., 2009) and brand choice (Berger et al., 2007). 
CFRI 11,2

\section{4}

Despite the benefits from more options, researchers propose information overloading from choice proliferation by suggesting that the overabundance of options may lead to less motivation to make a final decision (Fasolo et al., 2007; Mick et al., 2004; Mogilner et al., 2008). One stream of studies explores the negative consequences on consumers of choice proliferation, which induces failure to make a final choice (Sethi-Iyengar et al., 2004), decreased satisfaction with the chosen option (Chernev, 2003a) or an increase in negative emotions, such as disappointment and regret (Schwartz, 2000). Another stream of studies tries to answer the mechanisms of choice proliferation's effects on consumers' final decisions. Shafir et al. (1993) find that the presence of too many options decreases differentiation between options and becomes barrier for consumers to make the best option. In line with Shafir et al.'s studies, Messner and Wänke (2011) also find that evaluating a larger assortment size requires more cognitive effort, which frustrates consumers who must compare options among a complex assortment with different attributes, and in turn induces the fear of not being able to choose the best option (Iyengar et al., 2006).

\subsection{Pension plan studies}

In financial area, similar researches with the assortment design studies are the researches in studied pension design. Pension plans share similarities with crowdfunding rewards menus in providing several options for investors to choose. However, the options in pension plans are funds but the options in rewards menus are products and services related to the crowdfunding projects.

Related pension plan studies examine investors' investing strategies and investment behaviors. Especially, effects of the fraction of equity funds and the total number of funds in the plan are examined. Benartzi and Thaler (2001) find that the proportion invested in stocks depends on the proportion of stock funds in the plan because investors' diversification heuristic leads to the " $1 / \mathrm{n}$ " strategy: "dividing contributions evenly across the funds offered". However, Huberman and Jiang (2006) find that the tendency of allocating contributions evenly across funds weakens with the number of funds used and that participants' propensity of contributing to equity funds is not very sensitive to the equity funds fraction when the number of funds in the pension plan is large. In line with this conclusion, studies also find that large choice sets lead to stronger preference for simple and easy-to-understand options and hence investors allocate large portion of assets into money markets and bond funds at the expense of equity funds (Iyengar and Kamenica, 2010). Others explore the conditions of large choice sets' negative effect on investment decision and find that the negative effect applies to less experienced investors and more experienced investors prefer a larger funds set (Kida et al., 2010).

\section{Hypotheses development}

Researchers pay attention to the relationship between the number of reward options and crowdfunding success, since reward hunting is one of the main contribution motivations in reward-based crowdfunding platforms (Gerber and Hui, 2013). However, there are two competing findings about the effect of the reward options. One group of researchers believes in a positive effect of the number of reward options because of the wider range of choices to satisfy the diverse contribution motivations (Kunz et al., 2017; Zhou et al., 2018), since the backers have a variety of incentives to support (Gerber and Hui, 2013). The opposite side believes a negative relationship exists between crowdfunding success and the number of reward options because of information overloading (Chen et al., 2016; Leite and Moutinho, 2012), which causes the backers' inability to locate what is relevant and their overlooking of what is most crucial among relevant data (Herbig and Kramer, 1994).

To summarize, the above analysis suggests that when the number of reward options is few, adding to the number of reward options enables backers to find their optimal option and 
provide them with the psychological benefits of having more choices. However, when the number of reward options is high, backers are faced with too many options, and in hence, information overloading discourages them from making a final decision. Hence, we hypothesize the following:

H1. There exists an inverted U-shaped relationship between the success rate and the number of reward options.

In consumer behavior studies, researchers have found that price is one of the most commonly used cues to infer products quality based on the rationale that higher price reflects finer design and better materials of the product. Empirical research also finds that prices are positively related with both the actual quality (Lichtenstein and Burton, 1989) and the perceived quality of the products (Teas and Agarwal, 2000). In addition, prices are used as criteria to judge products' quality and facilitate purchase decisions when consumers are unfamiliar with the products. Researchers have found differentially priced assortment leads to higher purchase probability and choice satisfaction when consumers are uncertain of their preferences on products' non-price attributes (Chernev, 2006; Choi et al., 2018), because consumers are likely to use prices as diagnostic cues for making inferences under high preference uncertainty circumstance (de Langhe et al., 2014). In this paper, we use Price Differentiation to indicate the extent of price dispersion of reward prices, which is calculated as the coefficient of variance of reward prices.

In Hypothesis 1, we argue that the inverted u-shaped relationship between crowdfunding success and the number of reward options is caused by the tradeoffs between the marginal benefits and costs of additional alternative.

In the benefits aspect, additional option increases the chance of finding the close matches to optimal choice (Baumol and Ide, 1956; Wright and Barbour, 1975) and provides the perception of choice freedom (Reibstein et al., 1975). However, the marginal benefits from additional option tend to decrease with the increase in total number of options (Chernev and Hamilton, 2009). When taking price into consideration, more dispersed prices reflect more differentiated quality of products and lead to higher benefits at the same number of options. More intuitively, we provide Figure 1 to facilitate illustrations. On the left side of Figure 1, the Benefits-High PD and Benefits-Low PD lines are the benefits-options relationships under high/low price differentiation circumstances.

In the costs aspect, the cost of additional option is the increased cognitive load of evaluating the options (Messner and Wänke, 2011). And the marginal cost is increased with the number of options if evaluating options concerns comparisons between any two options. One source of the cognitive load is from the uncertainty of preferences on non-price attributes of products (Chernev, 2003b). Crowdfunding applies to the preferences uncertainty circumstance because the rewards are usually new to the market. However, cognitive load caused by preference uncertainty can be mitigated through using differentiated prices as diagnostic cues for inference making and simplifying decision making (Chernev, 2006; Choi et al., 2018). Hence, more dispersed prices leads to lower evaluating cost at the same number of options. On the left side of Figure 1, the Costs-High PD and Costs-Low PD lines are the costsoptions relationships under high/low price differentiation circumstances. Interactions A and $\mathrm{B}$ are the points when the net benefits comes to 0 under the high/low price differentiation circumstance. A simple description of the relationships between net benefits and the number of reward options under high/low price differentiation circumstances is provided on the right side of Figure 1. Therefore, we hypothesize the following:

H2. Price differentiation moderates the curvilinear relationship between the number of reward options and the crowdfunding success rate. 


\section{CFRI}

11,2

\section{6}

Figure 1.

Relationships between the number of options and the benefits/costs under the high/low price differentiation
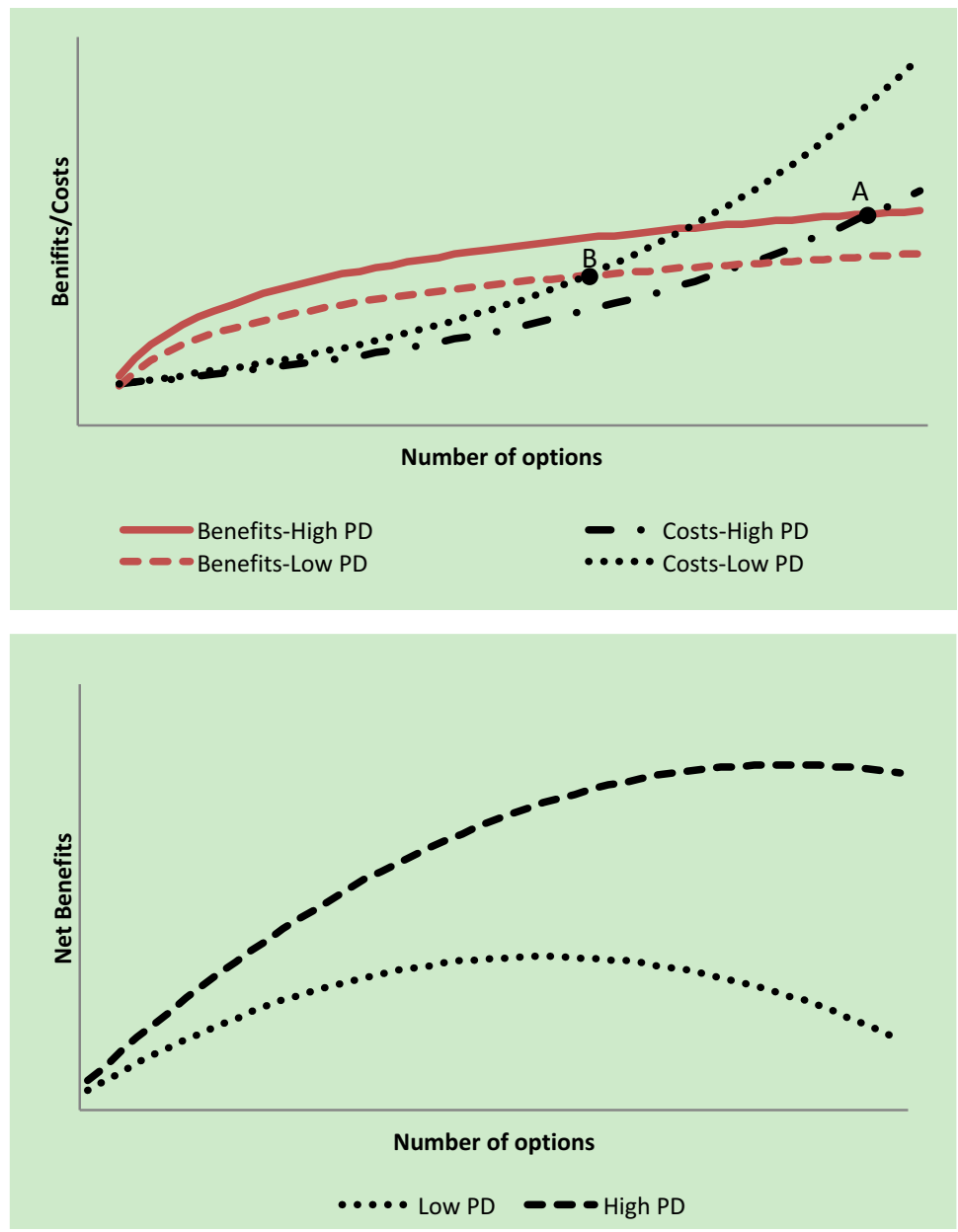

\section{Study context and data collection}

\subsection{Study context}

We collect proprietary data from one of the largest crowdfunding platforms in China, Zhongchou.com [1]. The crowdfunding platform, "zhongchou.com" or "zhongchou.cn", established in February 2013, was a reward-based crowdfunding platform, belonging to the Fintech company NCF group (http://www.ncfgroup.com). It aimed at helping small entrepreneurs or individuals to fulfill their creative ideas by providing money solicited from the crowds. Since its inception in 2013, Zhongchou had hosted more than 68,000 projects and solicited more than 250 million RMB from about 1.6 million backers till 2017. As a reward-based crowdfunding platform, Zhongchou provided rewards as returns to backers and the rewards were usually products or services produced by the crowdfunding projects. This crowdfunding model is different from three other models, debt-based, equitybased, and donation-based platforms, which provide interest, equity and nothing as returns separately. 
More specifically, on Zhongchou, project creators firstly launched their projects with detailed descriptions, funding goals and funding time. In the funding period, the potential backers browsed the projects and chose a project to support according to their own preferences. Only when the project raised enough money exceeding their funding goal before the funding deadline, the project creator could get the fund after deducting an administrative expense paid to the platform. Then the project creators would send the rewards to the backers after products preparation period.

\subsection{Data collection}

We collected our data through a web crawler, realized by PHP scripts in 2015. Our observational period was from January 2014 to December 2015. Data of 2013 was not included because the platform just started operation and went through a lot of changes and projects started in 2013 were also in a trial status and not representative enough. In our observation period, we collected data from 9,314 projects. The data we collected could be divided into three parts: the crowdfunding outcome, the attributes of the crowdfunding projects, and the information about the project creator.

In the crowdfunding outcome part, we collect the total amount of money pledged and the total number of backers of each project. In the project attributes part, we have data about the funding goal of each project, the start and end dates, the project category, the project content and the reward options. In the project creator characteristics part, we have information on date of joining the platform, geographical information, and whether they disclose their social media account (i.e. whether they are on Weibo, a blog, and WeChat), citizenship ID and business licenses.

\section{Empirical methodology and variables}

\subsection{Curvilinear relationship between crowdfunding success and the number of reward options}

We use a binary variable to depict whether a project is successful in raising money or not. When the total support amount is larger than the target amount, the project creator can obtain the entire support amount, and the binary variable is 1 ; otherwise, it is 0 . We apply the linear probability model (LPM) for our main analysis. Although the LPM estimator has the drawbacks that the estimated probabilities are not bounded on the unit interval (Horrace and Oaxaca, 2006), the results for linear and logistic significance turn out to be nearly identical when the absolute percentage of the dependent variable is between $20 \%$ and $80 \%$ (in our case, the average success rate is 35\%) (Angrist and Pischke, 2008; Hellevik, 2009; Long and Freese, 2014). The LPM model has the merits: the sum of components corresponds to the bivariate association and presents absolute differences in percentage points, facilitating the interpretation. We also apply logistic and probit estimations as alternative models for robustness checks.

The main model we use to detect the curvilinear relationship between crowdfunding success and the number of reward options is as follows:

$$
\begin{aligned}
\text { Success }_{i}= & \beta_{0}+\beta_{1} \cdot \text { Options }_{i}+\beta_{2} \cdot \text { Options }_{i}+\gamma \cdot \text { Project_Attributes }_{i} \\
& +\delta \cdot \text { Initiator_Atrributes }_{i}+\zeta \cdot \text { ProjectCategory }_{i}+\eta \cdot \text { StartMonth }_{i} \\
& +\theta \cdot \text { EndMonth }_{i}+\lambda \cdot \text { Locations }_{i}+\phi \cdot I D_{i}+\epsilon_{i}
\end{aligned}
$$

Success $_{i}$ represents whether the project raises enough money during the fund-raising period. Options $_{i}$ is the independent variable, which denotes the number of reward options a crowdfunding project provides. Usually, a crowdfunding project creator defines different 
CFRI 11,2

\section{8}

levels of reward options by different quantities or quality (Hu et al., 2015). Each project has at least one reward option, and each reward option is given a predefined price and a specific configuration of tangible or intangible rewards. Options $2_{i}$ is the square term of Options ${ }_{i}$, by which we can examine the nonlinear relationship between crowdfunding success and the number of reward options. There are two sets of covariates in our model Project_Atrributes $i$ and Initiator_Attributes, used to control for the attributes of project and the project creator characteristics. Besides, several categorical variables are included in our model to control potential unobserved within-group effects. These categorical variables include project type, the start and end months and project creators' locations as well as their ID types.

More specifically, regarding crowdfunding project attributes, we have the information about the monetary targets, the durations for fundraising, the project descriptions and the price ranges of the reward options. These variables are discussed broadly in the extant literature. In particular, funding goal is predefined by the project creator and is found to weaken the association between prior capital accumulation and visitor contribution (Burtch et al., 2018). The duration of a project is the time length of funding period. A long duration can allow enough exposure to the backers, but a too long-duration can also serve as a signal that the creator lacks confidence (Mollick, 2014). In addition to the literature in the business venture area emphasizing the importance of business proposals (Carpentier and Suret, 2015; Macmillan et al., 1985), studies in the crowdfunding area also point out the importance of the crowdfunding description by investigating the effect of different kinds of media (Koch and Siering, 2015; Wang et al., 2019) and the sentiment expressed in the project description (Yuan et al., 2016; Zhou et al., 2018). We also include the price range variable in our model, which is defined as the range of lowest option price and highest option price of one project, Price range is broadly studied by researchers as a measure of price dispersion (Baye et al., 2006).

In project creator attributes aspects, information of creators includes whether they disclose their social media information, citizenship ID or business license, and their geographical information as well as the day when they joined the platform. More specifically, we use a binary variable to describe whether project creator discloses their social media information for the following reasons. Project creators choosing to disclose their social media account may have unobserved homophily compared to those who do not. Besides, backers can be more informed of project creators by their social media account and infer the likelihood of crowdfunding success. In addition, inspired by literature in business venture which explores the relationship between the creators' pre-ownership and venture performance (Macmillan et al., 1985; Stuart and Abetti, 1990), we construct the variable Experience as the time interval between project start day and the day when project creator joined the platform to represent creator's crowdfunding experience. ID information and geographical information are used as categorical variables in our model, which are discussed in the following separately.

We also include several vital categorical variables, including project start and end month, project type and creators' ID type as well as their locations. By including the start and end month, we control potential time effect. In addition, researchers have found that projects belonging to different categories may have different success rate (Belleflamme et al., 2013; Cai et al., 2017). Therefore, project type is included to control potential inter-category differences in success. In particular, on reward-based crowdfunding platforms, rewards are products or services related to the crowdfunding projects. Rewards of projects in the same project category may share similar patterns and be seen as in the same rewards type. Hence, project category variable also controls potential effect from different rewards types. For the ID type information, projects in Zhongchou can either be launched by an individual or an organization, which can be distinguished by the ID types (Individual Identification and/or Business License) disclosed to the platform. Lastly, we also control the effect of project 
creators' geographical information (Lin and Viswanathan, 2016) by classifying locations into east, middle, west and northeast of China.

\subsection{The moderating effect of funding scheme price differentiation on the relationship between crowdfunding success and the number of reward options}

We use the following model to detect the moderating effect of funding scheme price differentiation on the curvilinear relationship between crowdfunding success and the number of reward options:

$$
\begin{aligned}
\text { Success }_{i}= & \beta_{0}+\beta_{1} \cdot \text { Options }_{i}+\beta_{2} \cdot \text { Options }_{i}+\beta_{3} \cdot \text { PriceDifferentiation }_{i} \\
& +\beta_{4} \cdot \text { PriceDifferentiation }_{i} \cdot \text { Options }_{i}+\beta_{5} \cdot \text { PriceDifferentiation }_{i} \cdot \text { Options }_{i} \\
& +\gamma \cdot \text { Project_Atrributes }_{i}+\delta \cdot \text { Initiator_Attributes }_{i}+\zeta \cdot \text { ProjectCategory }_{i} \\
& +\eta \cdot \text { StartMonth }_{i}+\theta \cdot \text { EndMonth }_{i}+\lambda \cdot \text { Locations }_{i}+\phi \cdot I D_{i}+\epsilon_{i}
\end{aligned}
$$

PriceDifferentiation $_{i}$ denotes the extent of how the prices of reward options are differentiated from each other. We use the coefficient of variance to measure the differentiation of reward option prices, which is calculated as Price_Std ${ }_{i} / \operatorname{Price}_{-} \mathrm{Mean}_{i}$. Price_Std ${ }_{i}$ is the standard deviation of option prices in crowdfunding project $i$ and Price_Mean ${ }_{i}$ is the mean of option prices in crowdfunding project $i$.

\section{Empirical analysis and results}

\subsection{Summary statistics and correlation matrix}

Table 1 provides the summary statistics of the variables used in this study. We have 9,314 observations of crowdfunding projects from several categories, including agriculture, entertainment, charity, technology, art, publishing, and others. The average success rate of our sample is $35 \%$, which is considerably low and near the success rate disclosed by Kickstarter, the largest reward-based crowdfunding platform in the world. The average support amount per project is $14,813.60 \mathrm{RMB}$, with the average funding goal near 43,341.92 $\mathrm{RMB}$. The average fulfilment ratio of the project is near $73 \%$. In addition, the average time for the project to raise money is nearly 6 weeks. Of these projects, $69.82 \%$ are located in the eastern part of China and most of the project creators reveal their IDs to the platform.

Table 2 shows the correlative matrix of the dependent variables and independent variables. The proxy variables for success are significantly correlated with most of the independent variables at the 0.05 level. In particular, the two vital variables, the number of reward options and price differentiation, are positively correlated with crowdfunding success. In addition, the VIFs of the independent variables are all less than 10 , which passes the multicollinearity test.

\subsection{Empirical results}

Before running the main models, we draw the histogram of our focal independent variable, the number of reward options. As in Figure 2, the distribution of the number of reward options is right-skewed, and the projects with fewer than 17 reward options account for $99.8 \%$ of all the projects. The project with the number of reward options larger than 17 only accounts for $0.2 \%$ of all the projects, but the largest number of reward options in our sample is 36 . Hence, we trim our sample by excluding samples outside the interval of $1 \%-99 \%$ (Dixon, 1960) to exclude the effects from outliers. We also use the log transformation of other control variables to avoid non-normality.

We test our hypothesis in four steps. First, we run regression of all the control variables as the base model, Model 0; second, we add the number of reward options into the base model to
Crowdfunding success and reward options 


\section{CFRI 11,2}

$\underline{240}$

\begin{tabular}{|c|c|c|c|c|c|c|}
\hline Variables & Variables definitions & Mean & SD & Min & $\operatorname{Max}$ & $N$ \\
\hline Success & $\begin{array}{l}\text { The project raises enough money } \\
\text { to meet its funding goal (yes }=1 \text {; } \\
\text { otherwise }=0 \text { ) }\end{array}$ & 0.35 & 0.48 & 0 & 1 & 9,314 \\
\hline TotalSupport & Total money supported (in RMB) & $14,813.60$ & $116,308.00$ & 0 & $5,660,024$ & 9,314 \\
\hline FulfilmentRatio & $\begin{array}{l}\text { Ratio of money supported to } \\
\text { funding goal }\end{array}$ & 0.73 & 2.45 & 0 & 99 & 9,314 \\
\hline Backers & $\begin{array}{l}\text { Total number of backers in one } \\
\text { project }\end{array}$ & 42.59 & 233.44 & 0 & 7,983 & 9,314 \\
\hline AverageSupport & $\begin{array}{l}\text { Average support per backer in } \\
\text { one project }\end{array}$ & 290.64 & $2,384.14$ & 0 & 100,000 & 9,314 \\
\hline Text length & Text length in project description & $5,790.38$ & $4,433.66$ & 159 & 60,458 & 9314 \\
\hline Pictures & $\begin{array}{l}\text { Number of pictures in project } \\
\text { description }\end{array}$ & 10.44 & 7.81 & 0 & 94 & 9314 \\
\hline Videos & $\begin{array}{l}\text { Number of videos in project } \\
\text { description }\end{array}$ & 0.29 & 0.72 & 0 & 16 & 9314 \\
\hline Options & $\begin{array}{l}\text { Number of reward options of one } \\
\text { project }\end{array}$ & 6.07 & 2.18 & 1 & 36 & 9,314 \\
\hline Options2 & Squared term of Options & 41.58 & 35.32 & 1 & 1,296 & 9,314 \\
\hline Price range & Highest price minus lowest price & $16,770.99$ & $186,464.32$ & 0 & $10,000,000$ & 9,314 \\
\hline $\begin{array}{l}\text { Price } \\
\text { differentiation }\end{array}$ & Coefficient of variance of prices & 1.38 & 0.47 & 0 & 5 & 9,314 \\
\hline Tagert amount & minimum funding Goa (in RMB) & $43,341.92$ & $215,543.48$ & 10 & $10,000,000$ & 9,314 \\
\hline Duration & $\begin{array}{l}\text { Time length of funding period (in } \\
\text { day) }\end{array}$ & 41.12 & 22.87 & 1 & 322 & 9,314 \\
\hline Experience & $\begin{array}{l}\text { Days between project start day } \\
\text { and the day when project initiator } \\
\text { joined the platform }\end{array}$ & 593.32 & 640.56 & 0 & 916 & 9,314 \\
\hline Social network & $\begin{array}{l}\text { Whether project creator discloses } \\
\text { social network information } \\
\text { (yes = } 1 \text {; otherwise }=0 \text { ) }\end{array}$ & 0.15 & 0.35 & 0 & 1 & 9,314 \\
\hline Log support & Log transform of TotalSupport & 5.93 & 3.43 & 0 & 16 & 9,314 \\
\hline Log fulfilment & Log transform of FulfilmentRatio & -2.14 & 2.10 & -5 & 5 & 9,314 \\
\hline Log backers & Log transform of Backers & 2.22 & 1.63 & 0 & 9 & 9,314 \\
\hline Log average & Log transform of AverageSupport & 3.70 & 2.15 & 0 & 12 & 9,314 \\
\hline Log textlen & Log transform of TextLength & 8.44 & 0.68 & 5 & 11 & 9,314 \\
\hline Log videos & Log transform of Videos & 0.18 & 0.34 & 0 & 3 & 9,314 \\
\hline Log target & Log transform of ProvisionPoint & 9.20 & 1.59 & 2 & 16 & 9,314 \\
\hline Log pricerange & Log transform of PriceRange & 7.22 & 2.06 & 0 & 16 & 9,314 \\
\hline Log duration & Log transform of Duration & 3.59 & 0.59 & 1 & 6 & 9,314 \\
\hline
\end{tabular}

detect the general relationship between the number of reward options and crowdfunding success, shown as Model 1; third, we add the squared term of the number of reward options into Model 1 to detect the curvilinear relationship, shown as Model 2; last, we add the price differentiation variable and its interactions with both the number of reward options and the squared term of the number of reward options into Model 2 to detect the moderating effect of price differentiation on the curvilinear relationship between the number of reward options and the crowdfunding success, as shown in Model 3. The empirical results are displayed in Table 3.

6.2.1 Curvilinear relationship between crowdfunding success and the number of reward options. As shown in Table 3, in Model 1, we can see that projects with one more option generally have a $1.8 \%$ higher success rate, considering that the average success rate of the platform is only $35 \%$, which suggests that the crowdfunding projects in this platform benefit from more options in general. After adding the squared term of the number of reward options 


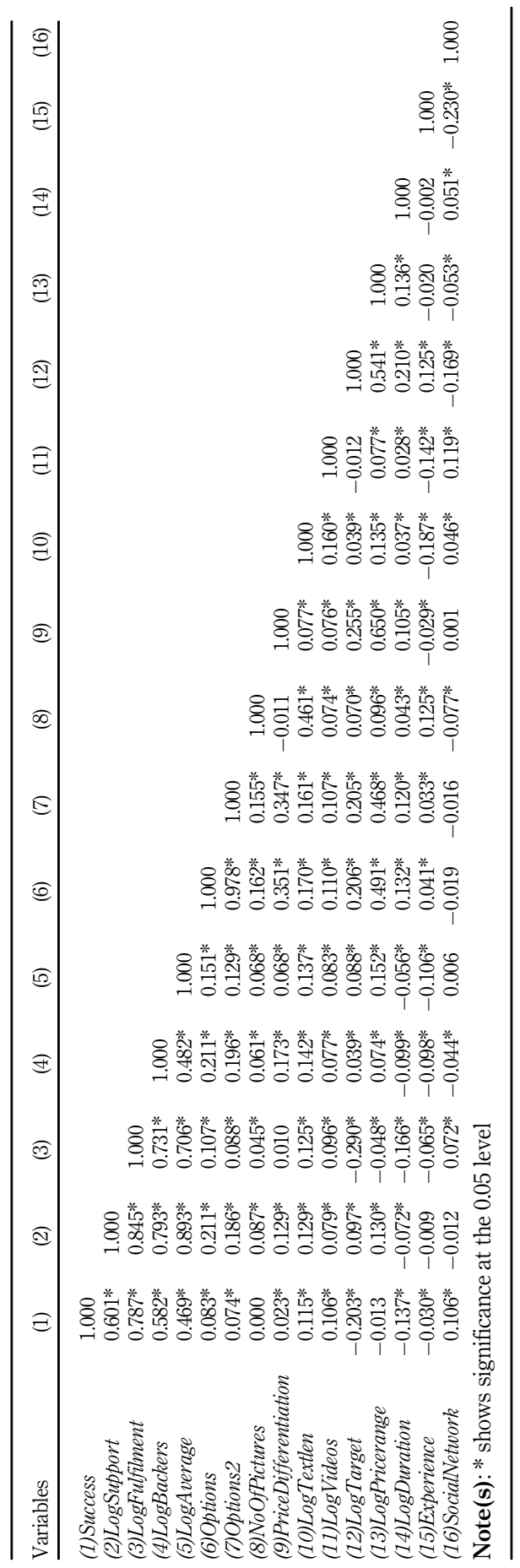

Crowdfunding

success and reward options

241

Table 2.

The correlative matrix of variables 


\section{CFRI 11,2}

\section{2}

Figure 2.

The distribution of the number of reward options

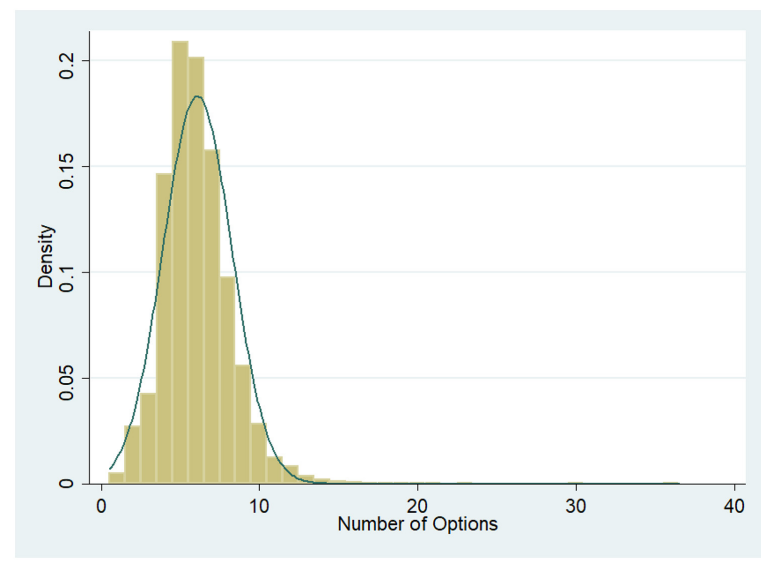

in Model 2, the coefficient of the number of reward options is still positive and larger than that in Model 1. However the coefficient of the squared term is significantly negative, which means that after crowdfunding success arrives at a peak, adding one more option has a negative effect on crowdfunding success. In our case, the optimal number of reward options is around 10. More specifically, when the number of reward options is 2 , adding one more option increases crowdfunding success by $5.2 \%$, which accounts for $14.9 \%$ of the average success rate $(35 \%)$. When the number of reward options is 10 , adding one more option has almost no effect on crowdfunding success, increased by $0.4 \%$ in our case. When the number of reward options is 12 , adding one more option decreases the crowdfunding success by $1.0 \%$.

6.2.2 Moderating effect of funding scheme price differentiation on the curvilinear relationship between the number of reward options and crowdfunding success. Model 3 shows the moderating effect of price differentiation and the number of reward options. The coefficients of the two interaction terms are significant, which means that the price differentiation moderates the relationship between crowdfunding success and the number of reward options. To illustrate the moderating effect more intuitively, we develop graphs to exhibit the moderating effects in Figure 3. We divide the data set into high price differentiation campaigns and low price differentiation campaigns by $1 \mathrm{SD}$ above and below the mean, which is a common practice in other studies (Faber and Walter, 2017; Richard et al., 2004). Among the low price differentiation campaigns ( $-1 \mathrm{SD})$, the slope analysis yields an inverted U-shaped relationship between the number of reward options, which is in consistence with our assumption that the less differentiated prices cannot decrease the cognitive load for backers to make a final decision when there are too many unfamiliar choices. Among the high price differentiation campaigns $(+1 \mathrm{SD})$, the slope analysis finds a positive relationship between the number of reward options and crowdfunding success. It could be explained that differentiated prices work as diagnostic cues to simplify the decision process and reduce the cognitive load for decision-making. Therefore, in this case, the optimal number of reward options is out of the actual range of the reward options in this sample and the relationship between crowdfunding success and the number of reward options are generally positive.

\section{Robustness checks and endogeneity test}

We use alternative models and alternative dependent variables to test the robustness of our results and perform a two-stage limited information maximum likelihood estimator to test any possible endogeneity problem. 


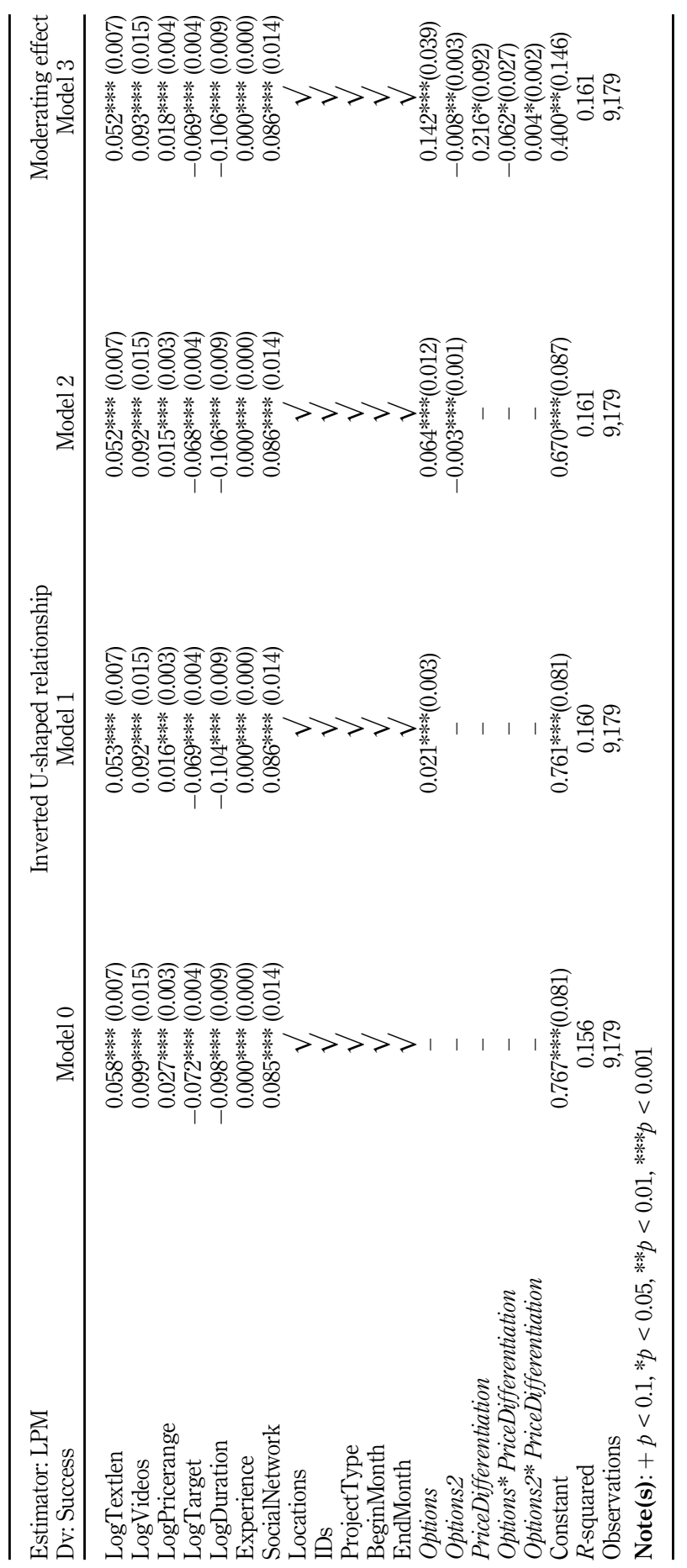

Crowdfunding

success and reward options

243

Table 3. Main analysis of the hypothesis 


\section{CFRI}

11,2

\section{4}

Figure 3.

Slop analysis of success rate and the number of reward options

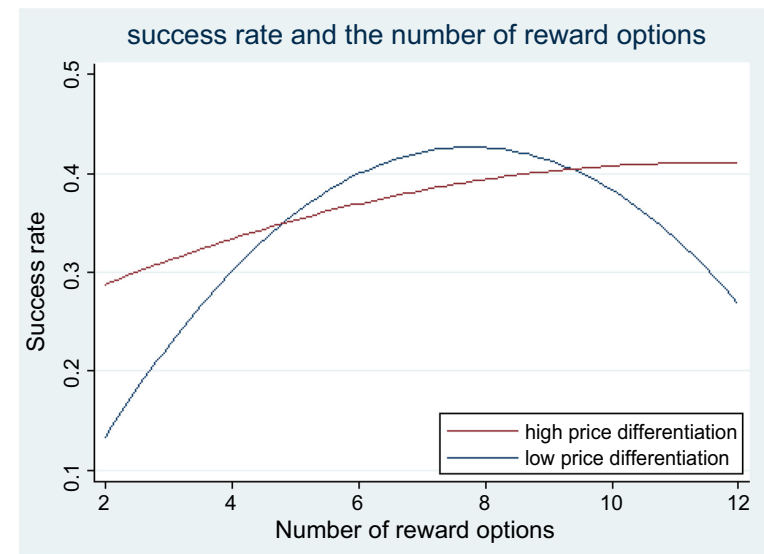

\subsection{Alternative estimators}

We perform our main analysis using the LPM estimator for its merits in presenting absolute differences in percentage points and facilitating our interpretation. Here, we use the logistic model and probit model as alternative estimators to test the robustness of our results because the dependent variable is a binary variable. The results are shown in Table 4.

For the robustness checks of $\mathrm{H} 1$ (the first and the second columns), the coefficients of the squared term in both the logistic model (the coefficient is fitted for using the log of odds ratio as the dependent variable) and probit model are significantly negative, which are qualitatively the same as our main analysis using the linear probability model. In addition, the optimal number of reward options is around 9, which is quite close to the results in the main analysis. We also use logistic regression and logit regression to check the robustness of the results for the moderating effect (in the third and fourth columns): the interaction terms are also significant and in the same direction as the results in the main analysis. In conclusion, the results for the two hypotheses remain robust when we use the two alternative estimators.

\subsection{Alternative dependent variables}

Using the binary variable to identify the success of crowdfunding in the main model cannot capture the nuances of crowdfunding outcomes, so we use two alternative continuous variables to describe the success of crowdfunding projects: the total support amount and the fulfilment ratio. The fulfilment ratio is the ratio of the total support amount to the funding goal. When it is larger than 1 , the crowdfunding project can obtain money; when it is less than 1 , the project cannot obtain money. More specifically, Fulfilment $i$ or the completion ratio is defined as follows:

$$
\text { Fulfillment }_{i}=\frac{\text { Total_Support }_{i}}{\text { Funding_Goal }_{i}}
$$

which is broadly adopted in crowdfunding studies as the proxy for crowdfunding success (Carr, 2013; Chen et al., 2016; Leite and Moutinho, 2012). The continuous variables capture more information than the yes-or-no binary variable and can compare the extent of how much the funding goal is fulfilled. Because the distribution of the total support amount and the fulfillment ratio are highly right-skewed, we use the log transformation of the two variables to obtain residuals that are approximately symmetrically distributed so that the patterns in the data are more interpretable (Tukey, 1977). 


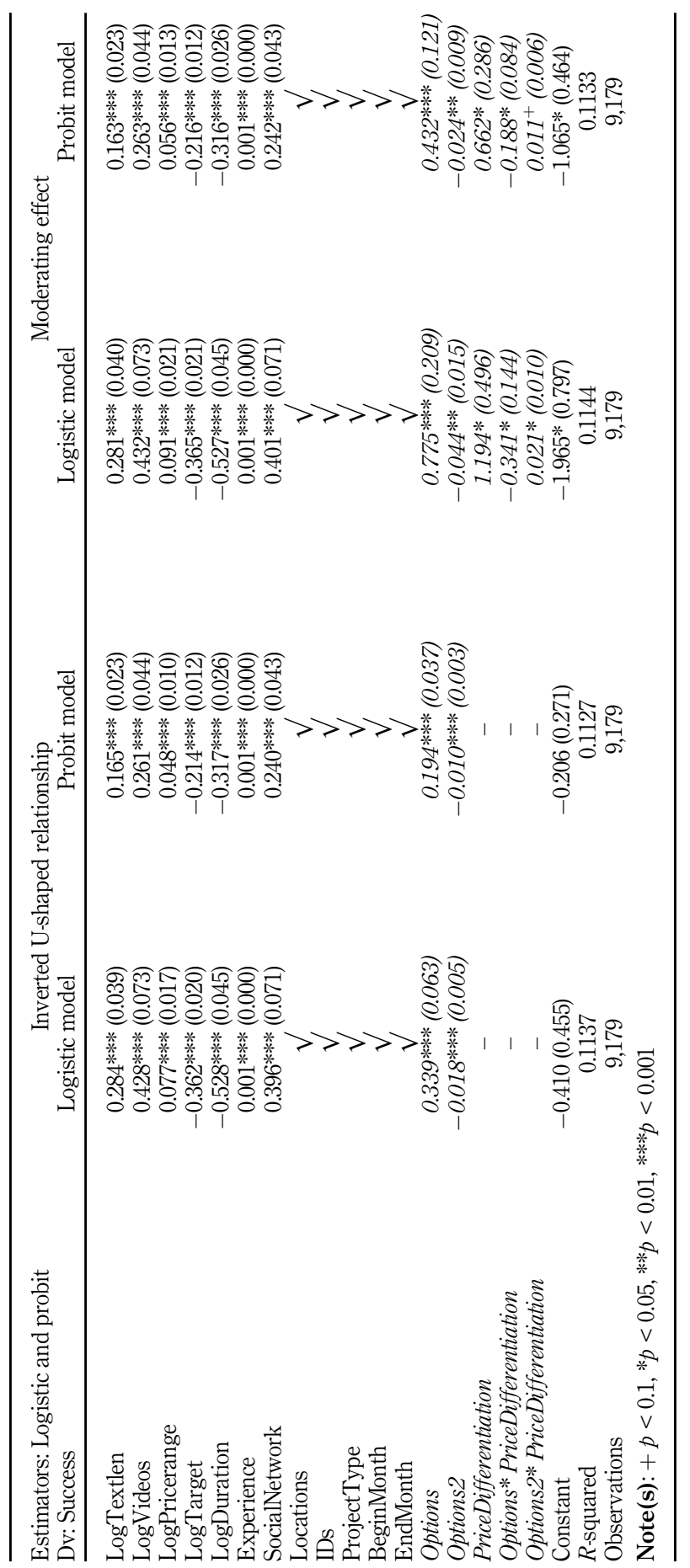

Crowdfunding success and reward options

245

Table 4. Robustness checks by alternative estimators 
CFRI 11,2

In addition, the total support amount is the product of the number of backers and the average support amount per backer. We also examine whether curvilinear relationships and the moderating effect exist between the number of reward options and the two intermediate variables for robustness checks.

As shown in Table 5, when we use the log of fulfillment ratio, total support amount, the log of the number of backers and the log of average support per backer as dependent variables separately, the coefficients in column (1) to (4) are qualitatively the same as the results in the main analysis, indicating that the inverted U-shaped pattern also occurs in the relationships of the number of reward options with the four alternative variables. In addition, the coefficients of the interaction terms in column (5) to (8) are also significant using the alternative variables as dependent variables separately, which are in the same direction as the results in the main analysis.

\subsection{Endogeneity test}

We employ the two-stage limited information maximum likelihood (LIML) estimator to test the potential endogeneity problem. The instrumental variables we use are the number of pictures in the project description part and its square term (Kelejian, 1971). When there are more reward options, the project creators tend to use more pictures to describe the rewards. Therefore the number of pictures is associated with the number of reward options. However, in zhongchou.com, the project description part also contains videos. Videos have been proved to play an important role on loan success in P2P platforms (Wang et al., 2019). When videos and pictures coexist, the backers tend to refer to videos to make decisions rather than pictures. The literature in the educational and psychological areas finds the superiority of studying videos over static pictures (Arguel and Jamet, 2009; Höffler and Leutner, 2007). In addition, researches in the crowdfunding area also do not find any significant influence of the number of photos on crowdfunding success (Beier and Wagner, 2015; Chen et al.,2016), which is consistent with our simple correlation analysis in Table 2 . We also use more solid statistical tests to check the under-identification and weak instrument problems of the instrumental variable. The histogram of the number of pictures is quite right-skewed. Hence, we trim our data by excluding outliers of the number of pictures outside the interval of $2.5-97.5 \%$.

First, we test whether the focal variables (the number of reward options and its square term) are exogenous with the Hausman test. The Hausman test statistic is $7.25(p<0.05)$, rejecting the null hypothesis that the focal variables are exogenous. Second, we use the number of pictures and its square term as the instrumental variables for the number of reward options and its square term, so the equation is exactly identified. Furthermore, for the under-identification test, the Kleibergen-Paap rk LM statistic is $15.72(\phi<0.001)$, rejecting the null hypothesis that the equation is under-identified. For the weak instruments test, the Cragg-Donald Wald F statistic is 11.38, exceeding its Stock-Yogo critical value of 7.03 (we can reject the null hypothesis under the i.i.d assumption by supposing we are willing to accept at most a rejection rate of $10 \%$ of a nominal $5 \%$ Wald test). The Kleibergen-Paap rk Wald $\mathrm{F}$ statistic is 8.02, exceeding the Stock-Yogo critical value of 7.03 again (we can also reject the weak instruments hypothesis when we drop the i.i.d assumption by supposing we are willing to accept at most a rejection rate of $10 \%$ of a nominal $5 \%$ Wald test). However, the KleibergenPaap rk Wald F statistic is still relatively small. Hence, we choose the LIML estimator to test the endogeneity problem because the LIML estimator is less biased, more efficient and performs better in weaker instruments (Angrist and Pischke, 2008).

We synthesize the first stage and second stage results of the LIML estimator and the results from LPM in Table 6. As we can see, the coefficients of the instrumental variables in the 1st stage are significant, suggesting the relevant relationships between the instrumental variables and the endogenous variables. Because we use the number of pictures and its 


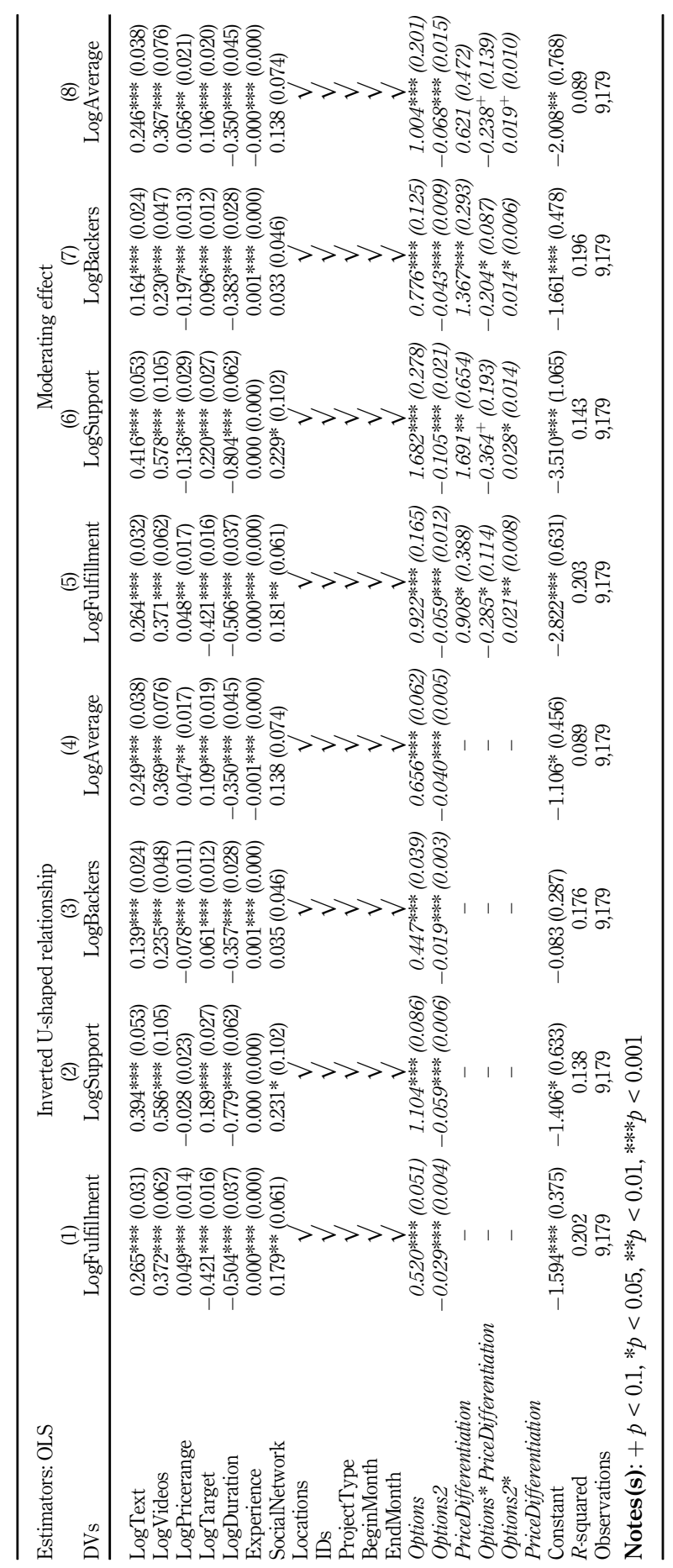

Crowdfunding

success and reward options

247

Table 5.

Robustness checks by alternative dependent variables 
CFRI

11,2

Inverted U-shaped relationship

LIML

LPM

Estimator: LIML

and LPM 1st stage

DVs

Options

Options2

(Baseline

LogTextlen

LogVideos

LogPricerange

LogTarget

LogDuration

Experience

SocialNetwork

Locations

IDs

ProjectType

BeginMonth

EndMonth

Options

Options2

Constant

Observations

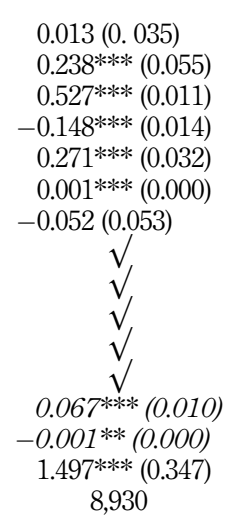

$0.042(0.468)$

$2.923 * * *(0.737)$

$6.492 * * *(0.143)$

$-1.599 * * * *(0.184)$

$2.976 * * *(0.430)$

$0.006 * * *(0.001)$

$-0.868(0.708)$

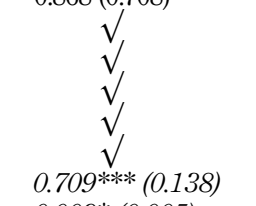

2nd stage

regression)

Success

Summary of endogeneity test statistics

Under identification test

Kleibergen-Paap rk LM statistic

15.72

$p$-Value

0.000

Weak identification test

Cragg-Donald Wald F statistic

11.38

Kleibergen-Paap rk Wald F statistic

8.02

Stock-Yogo weak ID test critical values: $10 \%$ maximal IV size

7.03

Table 6.

The endogeneity test by LIML estimator
Note(s): (1) $+p<0.1,{ }^{*} p<0.05,{ }^{*} p<<0.01$, ${ }^{* * *} p<0.001$; (2) Observations Difference is caused by trimming the outliers of NoOfPicutres

squared term as instrumental variables, it is not intuitive to check the relationships between endogenous variables and instrumental variables through the direction of the coefficients. When we consider the relationship between the number of reward options and the number of pictures, the result is shown in the first column of Table 6, which is an inverted U-shaped relationship. The maximal number of reward options occurs when the number of pictures equals 34. However, the largest number of pictures in the data after trimming the outliers is 31. Hence the relationship between the number of reward options and the number of pictures remains positive in the feasible region of the number of pictures. Meanwhile, when we consider the relationship between the square of the number of reward options and the square of the number of pictures, the relationship between them can be simplified as $y=\alpha \cdot \sqrt{x}+\beta \cdot x+\varepsilon$, where $y$ is the square of the number of reward options and $x$ is the square of the number of pictures. By the result shown in the second column of Table 6 , the relationship between the square of the number of options and the square of the number of pictures is also inverted U-shaped and the maximal value of the square of the number of reward options occurs when $x=\alpha^{2} / 4 \beta^{2}$. In our case, it is when the number of pictures is 39, which is larger than the maximal number of pictures. Hence, the relationship between the square of the number of reward options and the square of the number of pictures is also positive in the feasible region of the number of pictures in our dataset. 
In the 2nd stage, coefficients of the endogenous variables in the LIML are significant and of the same direction as the coefficients in the LPM estimator, which suggests that after resolving the endogeneity problem of our focal variables, the curvilinear relationship still exists between the number of reward options and crowdfunding success.

For the potential endogeneity problem of H2, as discussed in Bun and Harrison's theoretical paper in Econometric Reviews, the endogeneity bias can be reduced to 0 for the OLS estimator when the interaction term is considered and the coefficients of the interaction term are consistent (Bun and Harrison, 2019). Therefore, we only practice the LIML estimator to test the endogeneity problem for $\mathrm{H} 1$ as above.

\section{Discussion and conclusion}

This paper has several novel empirical findings for the reward menu design of crowdfunding projects. First, we examine the inverted U-shaped relationship between crowdfunding success and the number of reward options. When the number of reward options is relatively low, adding one more option has a marginally positive effect on crowdfunding performance because of the benefits of option value and optimal match. However, when the number of reward options is relatively high, adding one more reward option has a marginally negative effect on crowdfunding success because the imposed cognitive load on the backers discourages final decisions. Second, we find that the curvilinear relationship between crowdfunding success and the number of reward options is moderated by the price differentiation of the reward options. When the price differentiation is high, the differentiated prices of reward options increase the diversity perception of the rewards and serve as the diagnostic cue to reduce the cognitive load, which facilitate decision making even when the size of reward menu is large. However, when price differentiation is low, the diversity perception of the rewards is low and the cognitive load cannot be mitigated, which discourages decision making for comparing between similar options.

This paper adds to the literature in crowdfunding success determinants from the reward menu design aspects, based on theories in decision making for investment and purchasing. It is distinct from existing studies from perspectives of characteristics of creators and projects or investing dynamics, which are usually based on signal theory or herding behavior (Cai, 2018). This paper also parallels pension design studies by exploring reward menu design in the crowdfunding context. However, the reward menu design's effect on investing dynamics remains open for further researches. This study also has implications for crowdfunding creators and platform managers to take consideration of the proper number of reward options and a differentiated price menu.

\section{Note}

1. Zhongchou.com was shut down in 2019 because of market competition from big Internet companies in China, such as crowdfunding platforms of Taobao and JD, but it was a pioneer of Chinese crowdfunding platforms, among one of the earliest crowdfunding platforms. Some history pages could be obtained through searching "www.zhongchou.com" or "www.zhongchou.cn" on "wayback.archive.org", which is a nonprofit initiative of Internet Archive.

\section{References}

Agnew, J.R. and Szykman, L.R. (2005), "Asset allocation and information overload: the influence of information display, asset choice, and investor experience", Journal of Behavioral Finance, Vol. 6 No. 2, pp. 57-70.

Ahlers, G.K.C., Cumming, D., Günther, C. and Schweizer, D. (2015), "Signaling in equity crowdfunding", Entrepreneurship: Theory and Practice, Vol. 39 No. 4, pp. 955-980. 
CFRI 11,2

Angrist, J.D. and Pischke, J.-S. (2008), Mostly Harmless Econometrics: An Empiricist's Companion, Princeton University, London.

Arguel, A. and Jamet, E. (2009), "Using video and static pictures to improve learning of procedural contents", Computers in Human Behavior, Vol. 25 No. 2, pp. 354-359.

Bapna, S. (2019), "Complementarity of signals in early-stage equity investment decisions: evidence from a randomized field experiment", Management Science, Vol. 65 No. 2, pp. 933-952.

Baumol, W.J. and Ide, E.A. (1956), "Variety in retailing”, Management Science, Vol. 3 No. 1, pp. 93-101.

Baye, M.R., Morgan, J. and Scholten, P. (2006), Information, Search, and Price Dispersion, Indiana University, Kelley School of Business, Department of Business Economics and Public Policy, Bloomington.

Beier, M. and Wagner, K. (2015), "Crowdfunding success: a perspective from social media and E-commerce", Proceedings of the 36th International Conference on Information Systems (ICIS), Fort Worth, Texas, pp. 1-16.

Belleflamme, P., Lambert, T. and Schwienbacher, A. (2013), "Individual crowdfunding practices", Venture Capital, Vol. 15 No. 4, pp. 313-333.

Benartzi, S. and Thaler, R.H. (2001), "Naive diversification strategies in defined contribution saving plans", American Economic Review, Vol. 91 No. 1, pp. 79-98.

Berger, J., Draganska, M. and Simonson, I. (2007), "The influence of product variety on brand perception and choice", Marketing Science, Vol. 26 No. 4, pp. 460-472.

Betancourt, R. and Gautschi, D. (1990), "Demand complementarities, household production, and retail assortments", Marketing Science, Vol. 9 No. 2, pp. 146-161.

Block, J., Hornuf, L. and Moritz, A. (2018), "Which updates during an equity crowdfunding campaign increase crowd participation?”, Small Business Economics, Vol. 50 No. 1, pp. 3-27.

Borle, S., Boatwright, P., Kadane, J.B., Nunes, J.C. and Galit, S. (2005), "The effect of product assortment changes on customer retention”, Marketing Science, Vol. 24 No. 4, pp. 616-622.

Briesch, R.A., Chintagunta, P.K. and Fox, E.J. (2009), "How does assortment affect grocery store choice?”, Journal of Marketing Research, Vol. 46 No. 2, pp. 176-189.

Bun, M.J.G. and Harrison, T.D. (2019), "OLS and IV estimation of regression models including endogenous interaction terms", Econometric Reviews, Vol. 38 No. 7, pp. 814-827.

Burtch, G., Ghose, A. and Wattal, S. (2013), "An empirical examination of the antecedents and consequences of contribution patterns in crowd-funded markets", Information Systems Research, Vol. 24 No. 3, pp. 499-519.

Burtch, G., Ghose, A. and Wattal, S. (2014a). An empirical examination of peer referrals in online crowdfunding, Proceedings of the 35th International Conference on Information Systems (ICIS). Auckland, New Zealand, pp. 1-19.

Burtch, G., Ghose, A. and Wattal, S. (2014b), "Cultural differences and geography as determinants of online prosocial lending”, MIS Quarterly, Vol. 38 No. 3, pp. 773-794.

Burtch, G., Hong, Y. and Liu, D. (2018), "The role of provision points in online crowdfunding”, Journal of Management Information Systems, Vol. 35 No. 1, pp. 117-144.

Cai, C.W. (2018), "Disruption of financial intermediation by FinTech: a review on crowdfunding and blockchain", Accounting and Finance, Vol. 58 No. 4, pp. 965-992.

Cai, Z., Chan, J. and Liu, D. (2017), Better to Give than to Receive: Impacts of Donation-Based Contribution Schemes on Crowdfunding Outcomes, Workshop on Economics of Information Systems (WISE) 2017, The Korea Society of Management Information Systems, Seoul.

Carpentier, C. and Suret, J.-M. (2015), “Angel group members' decision process and rejection criteria: a longitudinal analysis", Journal of Business Venturing, Vol. 30, pp. 808-821. 
Carr, S. (2013), "Collective action and the financing of innovation: evidence from crowdfunding", SSRN Electronic Journal, Darden Business School Working Paper No. 2450510, available at: https:// ssrn.com/abstract $=2450510$.

Chen, S., Thomas, S. and Kohli, C. (2016), "What really makes a promotional campaign succeed on a crowdfunding platform?", Journal of Advertising Research, Vol. 56 No. 1, pp. 81-94.

Chen, X., Huang, B. and Ye, D. (2020), "Gender gap in peer-to-peer lending: evidence from China", Journal of Banking and Finance, Vol. 112, p. 105633.

Chernev, A. (2003a), "Product assortment and individual decision processes", Journal of Personality and Social Psychology, Vol. 85 No. 1, pp. 151-162.

Chernev, A. (2003b), "When more is less and less is more: the role of ideal point Availability and assortment in consumer choice", Journal of Consumer Research, Narnia, Vol. 30 No. 2, pp. 170-183.

Chernev, A. (2006), "Differentiation and parity in assortment pricing", Journal of Consumer Research, Vol. 33 No. 2, pp. 199-210.

Chernev, A. and Hamilton, R. (2009), "Assortment size and option attractiveness in consumer choice among retailers", Journal of Marketing Research, Vol. 46 No. 3, pp. 410-420.

Choi, C., Mattila, A.S. and Upneja, A. (2018), "The effect of assortment pricing on choice and satisfaction: the moderating role of consumer characteristics", Cornell Hospitality Quarterly, Vol. 59 No. 1, pp. 6-14.

Cumming, D.J., Johan, S.A. and Zhang, Y. (2019), "The role of due diligence in crowdfunding platforms", Journal of Banking and Finance, Vol. 108, p. 105661.

de Langhe, B., van Osselaer, S.M.J., Puntoni, S. and McGill, A.L. (2014), "Fooled by heteroscedastic randomness: local consistency breeds extremity in price-based quality inferences", Journal of Consumer Research, Vol. 41 No. 4, pp. 978-994.

Dixon, W.J. (1960), "Simplified estimation from censored normal samples", The Annals of Mathematical Statistics, Vol. 31 No. 2, pp. 385-391.

Dorfleitner, G., Priberny, C., Schuster, S., Stoiber, J., Weber, M., de Castro, I. and Kammler, J. (2016), "Description-text related soft information in peer-to-peer lending - evidence from two leading European platforms", Journal of Banking and Finance, Vol. 64, pp. 169-187.

Du, Z., Wang, K. and Li, M. (2019), "Promoting crowdfunding with lottery: the impact on campaign performance", Information and Management, Vol. 56, p. 103159.

Faber, A. and Walter, F. (2017), "The curvilinear relationship between age and emotional aperture: the moderating role of agreeableness", Frontiers in Psychology, Vol. 8, p. 1200.

Fasolo, B., McClelland, G.H. and Todd, P.M. (2007), "Escaping the tyranny of choice: when fewer attributes make choice easier", Marketing Theory, Vol. 7 No. 1, pp. 13-26.

Frydrych, D., Bock, A.J., Kinder, T. and Koeck, B. (2014), "Exploring entrepreneurial legitimacy in reward-based crowdfunding", Venture Capital, Vol. 16 No. 3, pp. 247-269.

Gafni, H., Marom, D. and Sade, O. (2019a), "Are the life and death of an early-stage venture indeed in the power of the tongue? Lessons from online crowdfunding pitches", Strategic Entrepreneurship Journal, Vol. 13 No. 1, pp. 3-23.

Gafni, H., Marom, D., Robb, A. and Sade, O. (2019b), "Gender dynamics in crowdfunding (kickstarter): evidence on entrepreneurs, investors, deals and taste based discrimination", SSRN Electronic Journal, available at: https://ssrn.com/abstract $=2442954$.

Ge, R., Feng, J., Gu, B. and Zhang, P. (2017), "Predicting and deterring default with social media information in peer-to-peer lending", Journal of Management Information Systems, Vol. 34 No. 2, pp. $401-424$.

Gerber, E.M. and Hui, J. (2013), "Crowdfunding: motivations and deterrents for participation”, ACM Transactions on Computer-Human Interaction, Vol. 20 No. 6, p. 32. 
CFRI 11,2

Glazer, R., Kahn, B.E. and Moore, W.L. (1991), "The influence of external constraints on brand choice: the lone-alternative effect", Journal of Consumer Research, Vol. 18 No. 1, p. 119.

Hardy, W. (2013), "How to perfectly discriminate in a crowd? A theoretical model of crowdfunding", University of Warsaw Faculty of Economic Sciences Working Papers, Vol. 16 No. 101, pp. 1-28.

Hellevik, O. (2009), "Linear versus logistic regression when the dependent variable is a dichotomy", Quality and Quantity, Vol. 43 No. 1, pp. 59-74.

Herbig, P.A. and Kramer, H. (1994), "The effect of information overload on the innovation choice process", Journal of Consumer Marketing, Vol. 11 No. 2, pp. 45-54.

Höffler, T.N. and Leutner, D. (2007), "Instructional animation versus static pictures: a meta-analysis", Learning and Instruction, Vol. 17 No. 6, pp. 722-738.

Horrace, W.C. and Oaxaca, R.L. (2006), "Results on the bias and inconsistency of ordinary least squares for the linear probability model”, Economics Letters, Vol. 90 No. 3, pp. 321-327.

Hotelling, H. (1929), "Stability in competition", The Economic Journal, Vol. 39 No. 153, p. 41.

Hu, M., Li, X. and Shi, M. (2015), "Product and pricing decisions in crowdfunding”, Marketing Science, Vol. 34 No. 3, pp. 331-345.

Huberman, G. and Jiang, W. (2006), "Offering versus choice in 401(k) plans: equity exposure and number of funds", The Journal of Finance, Vol. 61 No. 2, pp. 763-801.

Iyengar, S.S. and Kamenica, E. (2010), "Choice proliferation, simplicity seeking, and asset allocation", Journal of Public Economics, Vol. 94 Nos 7-8, pp. 530-539.

Iyengar, S.S., Wells, R.E. and Schwartz, B. (2006), "Doing better but feeling worse: looking for the 'best' job undermines satisfaction”, Psychological Science, Vol. 17 No. 2, pp. 143-150.

Kahn, B.E. and Lehmann, D.R. (1991), "Modeling choice among assortments", Journal of Retailing, Vol. 67 No. 3, pp. 274-299.

Kelejian, H.H. (1971), "Two-stage least squares and econometric systems linear in parameters but nonlinear in the endogenous variables", Journal of the American Statistical Association, Vol. 66 No. 334, pp. 373-374.

Kida, T., Moreno, K.K. and Smith, J.F. (2010), "Investment decision making: do experienced decision makers fall prey to the paradox of choice?", Journal of Behavioral Finance, Vol. 11 No. 1, pp. 21-30.

Koch, J.A. and Siering, M. (2015), "Crowdfunding success factors: the characteristics of successfully funded projects on crowdfunding platforms", 23rd European Conference on Information Systems, ECIS, 2015, Vol. 2015-May.

Kunz, M.M., Bretschneider, U., Erler, M. and Leimeister, J.M. (2017), “An empirical investigation of signaling in reward-based crowdfunding", Electronic Commerce Research, Vol. 17 No. 3, pp. 425-461, Springer US.

Lancaster, K. (1990), “The economics of product variety: a survey”, Marketing Science, Vol. 9 No. 3, pp. 189-206.

Leite, P. and Moutinho, N. (2012). Innovation through crowdfunding: a quantitative and qualitative analysis of kickstarter, 13th International CINet Conference, pp. 707-717.

Li, E. and Martin, J.S. (2019), "Capital formation and financial intermediation: the role of entrepreneur reputation formation", Journal of Corporate Finance, Vol. 59, pp. 185-201.

Li, X., Liu, B. and Tian, X. (2017), "Policy uncertainty and household credit access: evidence from peerto-peer crowdfunding”, SSRN Electronic Journal, doi: 10.2139/ssrn.3084388.

Li, E., Liao, L., Wang, Z. and Xiang, H. (2020), "Venture capital certification and customer response: evidence from P2P lending platforms", Journal of Corporate Finance, Vol. 60, p. 101533.

Lichtenstein, D.R. and Burton, S. (1989), "The relationship between perceived and objective pricequality”, Journal of Marketing Research, Vol. 26 No. 4, pp. 429-443. 
Lin, M. and Viswanathan, S. (2016), "Home bias in online investments: an empirical study of an online crowdfunding market", Management Science, Vol. 62 No. 5, pp. 1393-1414.

Lin, M., Prabhala, N.R. and Viswanathan, S. (2013), "Judging borrowers by the company they keep: friendship networks and information asymmetry in online peer-to-peer lending", Management Science, Vol. 59 No. 1, pp. 17-35.

Liu, D., Brass, D.J., Lu, Y. and Chen, D. (2015), "Friendship in online peer-to-peer lending: pipes, prisms, and relational herding", MIS Quarterly, Vol. 39 No. 3, pp. 729-742.

Long, J.S. and Freese, J. (2014), Regression Models for Categorical Dependent Variables Using Stata, 3rd ed., Stata Press, College Station.

Macmillan, I.C., Siegel, R. and Narasimha, P.N.S. (1985), "Criteria used by venture capitalists to evaluate new venture proposals", Journal of Business Venturing, Vol. 1 No. 1, pp. 119-128.

McAlister, L. (1982), "A dynamic attribute satiation model of variety-seeking behavior", Journal of Consumer Research, Vol. 9 No. 2, p. 141.

Messinger, P.R. and Narasimhan, C. (1997), "A model of retail formats based on consumers' economizing on shopping time", Marketing Science, Vol. 16 No. 1, pp. 1-23.

Messner, C. and Wänke, M. (2011), "Unconscious information processing reduces information overload and increases product satisfaction”, Journal of Consumer Psychology, Vol. 21 No. 1, pp. 9-13.

Mick, D.G., Broniarczyk, S.M. and Haidt, J. (2004), "Choose, choose, choose, choose, choose, choose, choose: emerging and prospective research on the deleterious effects of living in consumer hyperchoice”, Journal of Business Ethics, Vol. 52 No. 2, pp. 207-211.

Mogilner, C., Rudnick, T. and Iyengar, S.S. (2008), "The mere categorization effect: how the presence of categories increases choosers' perceptions of assortment variety and outcome satisfaction", Journal of Consumer Research, Vol. 35 No. 2, pp. 202-215.

Mollick, E. (2014), “The dynamics of crowdfunding: an exploratory study", Journal of Business Venturing, Vol. 29 No. 1, pp. 1-16.

Piva, E. and Rossi-Lamastra, C. (2018), "Human capital signals and entrepreneurs' success in equity crowdfunding", Small Business Economics, Vol. 51 No. 3, pp. 667-686.

Ralcheva, A. and Roosenboom, P. (2016), "On the road to success in equity crowdfunding", SSRN Electronic Journal, available at: https://ssrn.com/abstract=2727742.

Reibstein, D.J., Youngblood, S.A. and Fromkin, H.L. (1975), "Number of choices and perceived decision freedom as a determinant of satisfaction and consumer behavior", Journal of Applied Psychology, Vol. 60 No. 4, pp. 434-437.

Richard, O.C., Barnett, T., Dwyer, S. and Chadwick, K. (2004), "Cultural diversity in management, firm performance, and the moderating role of entrepreneurial orientation dimensions", Academy of Management Journal, Vol. 47 No. 2, pp. 255-266.

Schwartz, B. (2000), "Self-determination: the tyranny of freedom", American Psychologist, Vol. 55 No. 1, pp. 79-88.

Sethi-Iyengar, S., Huberman, G. and Jiang, G. (2004), "How much choice is too much? Contributions to 401(k) retirement plans", Pension Design and Structure, Oxford University Press, Oxford, pp. 83-96.

Shafir, E., Simonson, I. and Tversky, A. (1993), "Reason-based choice”, Cognition, Elsevier, Vol. 49 Nos 1-2, pp. 11-36.

Simons, A., Weinmann, M., Tietz, M. and vom Brocke, J. (2017). Which reward should I choose? Preliminary evidence for the middle-option bias in reward-based crowdfunding, Proceedings of the 50th Hawaii International Conference on System Sciences.

Sloot, L.M., Fok, D. and Verhoef, P.C. (2006), "The short- and long-term Impact of an assortment reduction on category sales", Journal of Marketing Research, Vol. 43 No. 4, pp. 536-548.

Statista (2019), Crowdfunding - Statistics \& Facts, Statista, New York, available at: https://www. statista.com/topics/1283/crowdfunding. 
CFRI

11,2
Stuart, R.W. and Abetti, P.A. (1990), "Impact of entrepreneurial and management experience on early performance", Journal of Business Venturing, Vol. 5 No. 3, pp. 151-162.

Teas, R.K. and Agarwal, S. (2000), "The effects of extrinsic product cues on consumers' perceptions of quality, sacrifice, and value", Journal of the Academy of Marketing Science, Vol. 28 No. 2, pp. 278-290.

Tietz, M., Simons, A., Weinmann, M. and Brocke, J.V. (2016), "The decoy effect in reward-based crowdfunding: preliminary results from an online experiment”, ICIS 2016 Proceedings, Dublin, Ireland, pp. 1-11.

Tukey, J.W. (1977), Exploratory Data Analysis, Addison-Wesley, Boston.

Vismara, S. (2016), "Equity retention and social network theory in equity crowdfunding", Small Business Economics, Vol. 46 No. 4, pp. 579-590.

Vismara, S. (2018), "Information cascades among investors in equity crowdfunding", Entrepreneurship: Theory and Practice, Vol. 42 No. 3, pp. 467-497.

Wang, N., Li, Q., Liang, H., Ye, T. and Ge, S. (2018), "Understanding the importance of interaction between creators and backers in crowdfunding success", Electronic Commerce Research and Applications, Vol. 27, pp. 106-117.

Wang, H., Yu, M. and Zhang, L. (2019), "Seeing is important: the usefulness of video information in P2P”, Accounting and Finance, Vol. 59 No. S2, pp. 2073-2103.

Weinmann, M., Tietz, M., Simons, A. and Brocke, J.V. (2017), "Get it before It's Gone? How limited rewards influence backers' choices in reward-based crowdfunding”, ICIS 2017 Proceedings, Seoul.

Wright, P. and Barbour, F. (1975), "The relevance of decision process models in structuring persuasive messages", Communication Research, Vol. 2 No. 3, pp. 246-259.

Yuan, H., Lau, R.Y.K. and Xu, W. (2016), "The determinants of crowdfunding success: a semantic text analytics approach", Decision Support Systems, Vol. 91, pp. 67-76.

Zhang, J. and Liu, P. (2012), "Rational herding in microloan markets", Management Science, Vol. 58 No. 5, pp. 892-912.

Zhou, M., Lu, B., Fan, W. and Wang, G.A. (2018), "Project description and crowdfunding success: an exploratory study”, Information Systems Frontiers, Vol. 20 No. 2, pp. 259-274. 


\section{Appendix}

\section{A case of crowdfunding project in Zhongchou.com}

We provide a case of art crowdfunding project of Zhongchou.com. This project was launched by a Chinese zither amateur, started on October 31, 2014 and ended on December 30. It aimed at popularizing Chinese zither culture by renting or selling Chinese zithers to backers. The money raised was used to fulfill three goals: establishing a Chinese zither pavilion in Shanghai for Chinese zither teaching and playing skills communication; providing charitable shows of Chinese zither to popularize Chinese zither culture; a long term goal to establish a Chinese zither manufacturing society.

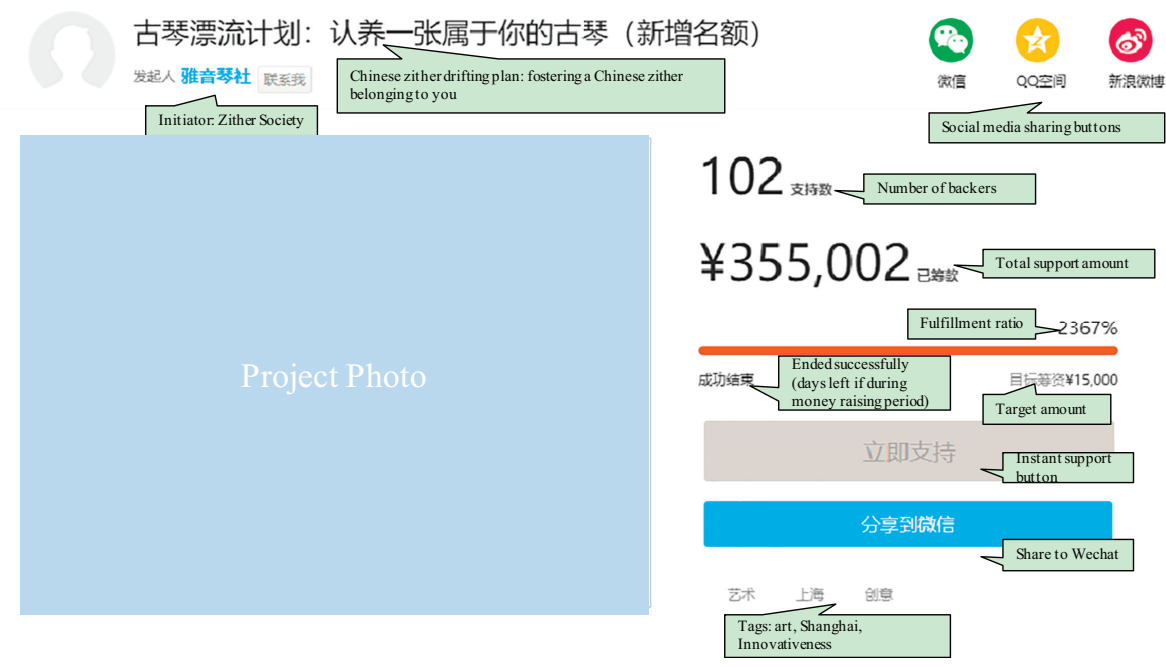

Figure A1. Project overview 
CFRI

11,2

256
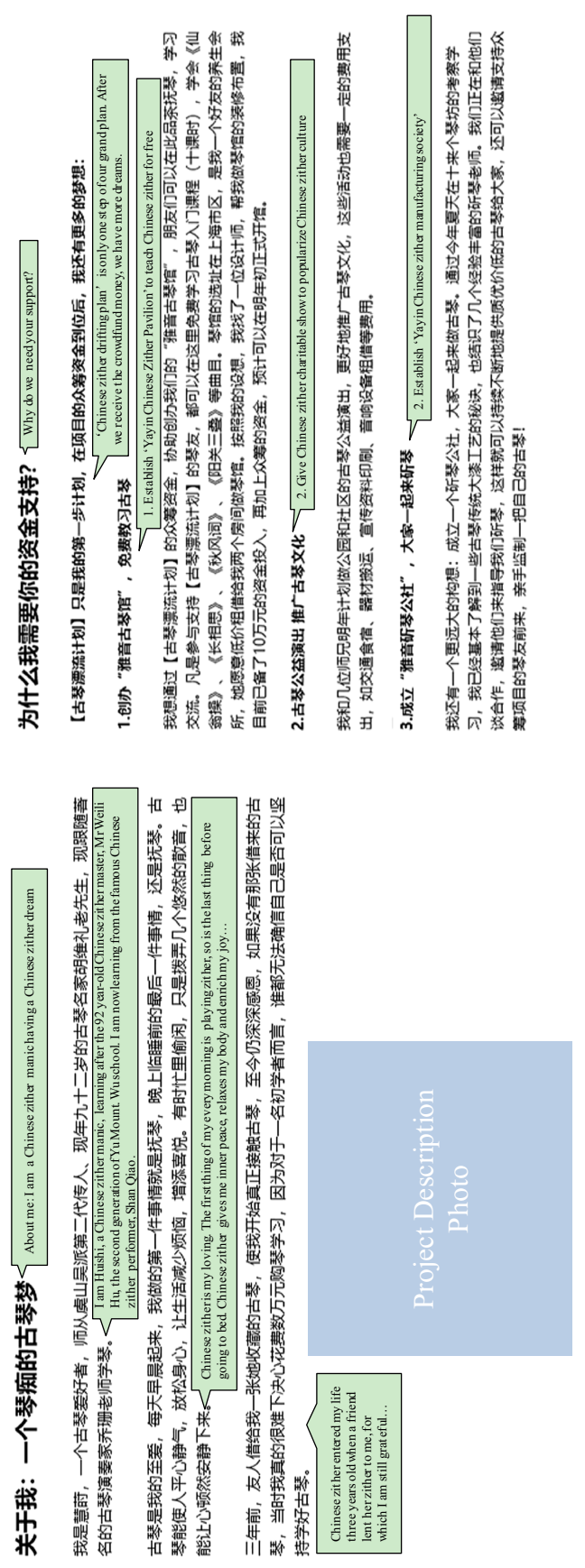

Figure A2.

Parts of project description 

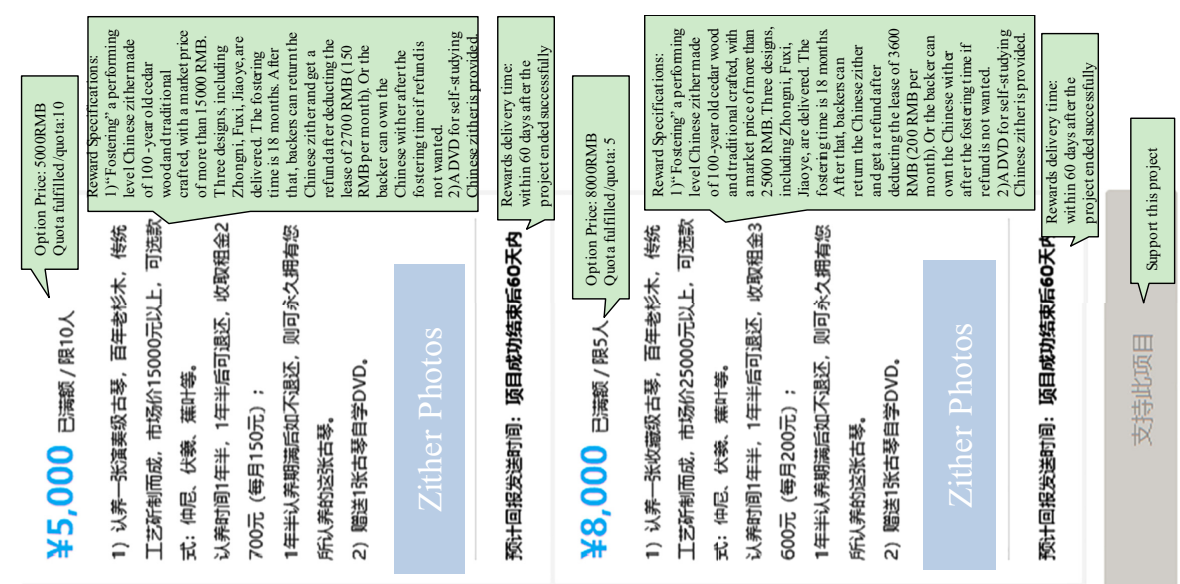

Crowdfunding

success and reward options
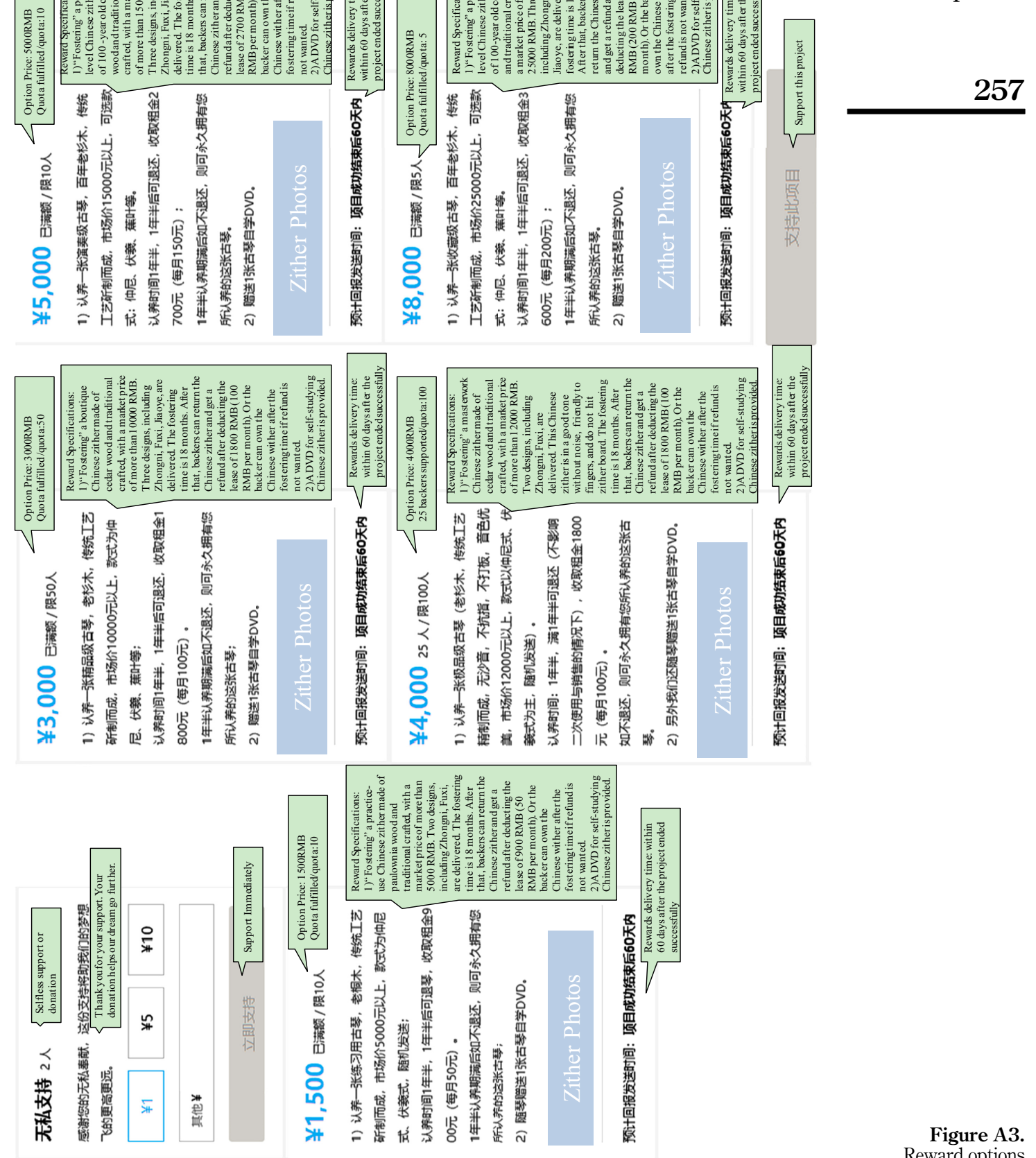

Figure A3. Reward options 
CFRI 11,2

A screenshot of the project page is provided, which could be divided into three parts. On the top of the project page is the project overview, which includes project title, project initiator, featuring picture, real-time number of backers, real-time support amount, days left, target amount, fulfillment percentage, project tags, and buttons to share to social media as well as a button for instant supporting. In this project, the project had finished raising money. The total support amount was 355,002 RMB from 102 backers, which was $2,367 \%$ of the target amount 15,000 RMB.

The second part is the project description, which usually contains text, photos and videos, describing the project in detail. There are no set patterns for project initiators to describe their projects. A figure about parts of the project description is provided in the following.

The third part is the reward options. The reward options are on the right of the page. The options are vertically displayed, with the lowest price on the top and highest price on the bottom. To exhibit the reward options conveniently, we list the reward options in three columns rather than one column in Figure A3. In this case, the project provides five reward options as well as one donation option. The donation option is a feature from the donation-based crowdfunding, and it only solicit money but do not provide rewards, which is quite different from reward option. In Zhongchou.com, the donation button is platform-mandated after August 2015. In our paper, we only considered the effect from the number of reward options. More specifically, the backer could "foster" a practice-use Chinese zither made of paulownia wood if supporting 1,500 RMB, a boutique Chinese zither made of cedar wood if supporting 3,000 RMB, a masterwork Chinese zither made of cedar wood if supporting 4,000 RMB, a performing level Chinese zither made of 100-year old cedar wood if supporting 5,000 RMB, and a collection level Chinese zither made of 100-year old cedar wood if supporting 8,000 RMB. As we can see the prices are differentiated. We use the coefficient of variance to measure price differentiation, which is defined as the extent of how prices of one project are different from each other. It is calculated as: PriceDifferentiation $=$ PriceMean/PriceStd. In this case, the price variation of this project is 0.507 .

\section{Corresponding author}

Zhigang Cai can be contacted at: wzann@sjtu.edu.cn

For instructions on how to order reprints of this article, please visit our website:

www.emeraldgrouppublishing.com/licensing/reprints.htm

Or contact us for further details: permissions@emeraldinsight.com 